\title{
Foreword: Changing the Story
}

\section{Antonio Oposa, Jr.}

\section{THE STORY OF BLAST FISHING}

Two fishermen throw dynamite into the sea to catch fish. Within the blast zone, all the fish are killed and all the corals underneath are reduced to rubble. There is very little chance of the fishermen being caught. But if they are caught, will sending them to prison after a long and draining trial bring back to life the fish and the coral reefs?

That is the frustration of the law.

Law punishes bad behavior. But what inspires good behavior? Is it the law? Or is it the human heart?

Science and law try to change the mind. When you change the mind, it can change again tomorrow. But when you change the heart, it is forever.

I say this after all the wounds of war and bruises of battle I have suffered in one lifetime. After long and painful struggles with the Philippine government and with environmental crime syndicates, using law as the weapon of choice to change human behavior, not much has changed. After an entire career of trying to right wrongs, I learned that I was wrong all along.

I realized that the greatest human hunger is not the hunger for food. It is the hunger of the human heart for appreciation.

I also learned that the greatest leaders are not human beings.

Emperors come and go; empires rise and fall. But the most powerful leaders, which live forever, are Inspiration and Hope. Inspiration fuels the fire of desire. Hope springs eternal.

\section{2. $\quad$ SHIFTING THE TIDE: FROM BAD TO GOOD STORIES}

Most of what is going on in the world is not bad. In fact, much of it is good. But why do we not hear of the good? Because bad news sells. And media is in the business of selling bad news designed to produce outrage and anger.

It is time to turn around the story and change the narrative 180 degrees, from constantly looking for the bad toward lenses that focus on the good. It is time to shine the spotlight on what is right and good. It is time to look for the good news; the success stories; the best efforts of humans making peace with the Earth. 
When people's efforts are recognized and appreciated, they feel validated, which boosts the rockets of their desire to reach for the stars. Others around those people will be inspired and their hearts also set on fire.

This is a hidden hope in each and every one of us for a better world - for us, for our children and for those yet to come. This hope has the power to multiply positive and happy energy a million-fold.

Scholars and experts can distill the lessons from the success stories and best efforts. They can then formulate principles into policy and put it into practice. This way, law may be used as just one of the tools for behavioral change. Other more powerful agents of change are culture, values, and an understanding by the human heart.

\section{THE WAY FORWARD}

May I congratulate the International Union for the Conservation of Nature (IUCN) Academy for this wonderful path-breaking work. It is a new way of looking at the world. "En este mundo, todo es según el color del cristal con que se mira" ("In this world, everything depends on the color of the glass we use to look at it").

We have been looking too much at the bad and the wrong. This is why we now suffer collective and chronic societal depression. Worse, we seem overwhelmed by the problems and feel helpless and hopeless. We are also suffering from paralysis by analysis. Too much thinking; too little doing. With the accelerating crisis of climate and of life itself, we need a new approach. We need to hurry up the process of real and transformative change. We can take a cue from leaders in this endeavor: Theodore Admimzoya, Trevor Daya-Winterbottom, Lye Lin-Heng, David Estrin, Anita Foerster, Yanmei Lin, Freedom Kai Phillips, Robert Percival, Amy Pickering and Nicholas Robinson.

From my heart of hearts, let me thank them for their wonderful stories - stories of the world we want. Special mention to goes to Liza Eisma-Osorio, Elizabeth Kirk and Jessica Steinberg Albin for patiently putting together this masterpiece of love and art. Special thanks also to Liza Eisma-Osorio for her excellent organizing of the most memorable IUCN Academy Colloquium in Cebu in June 2017.

It will take a worldwide effort to collect these good stories and excellent examples. This book, now in your hands, will be an important building block for the new and exciting journey ahead.

Together with you, dear friends - with your students and with our friends around the world - together we must, we can, and we will change the narrative. We will shine the spotlight of recognition on the good and the right.

Together, with kind words, we will multiply the goodness of the human heart. "Kind words do not just praise the goodness of others. Kind words have the power to change the destiny of the world."

Antonio Oposa, Jr. Normandy Chair for Peace 